While in Wales generally hiring fairs are held in May and November, in districts like South Pembroke, known to have been occupied by Scandinavians, the hiring fairs are in April and October, and they represent an old equinoctial division of the year. JohN GRIFFith.

\section{MARINE INVESTIGATIONS IN NORWAY.'}

THE work done by the Norwegians takes a fore1 most place amongst the fishery and marine investigations which have been carried out in recent years under the general guidance of the International Council, which was established in rgor to coordinate the researches of the different countries bordering on the North Sea. The present report gives a general review of this work in readable form, without being burdened with any excess of detail, such detail being reserved for special memoirs, some of which are already published.

The introductory account of the plan and organisation of the work is written by Dr. Johan Hjort, the director of the investigations, and sets forth in the clearest way that effective combination of precise and accurate scientific investigation with practical developments of commercial fisheries which has always specially characterised the work of this investigator. Hydrographical investigation, plankton research, the study of the bottom fauna, each has received its due share of care and attention equally with the study of the natural history of fishes and the experiments which have led to the establishment of new fisheries for cod and for deep-sea prawns off the Norwegian coast.

In one important respect Norway has been especially fortunate, that is in having had the use of a research steamer, the Michael Sars, designed and built for the particular work of fishery research, an advantage which a parsimonious Government has denied to those who have to carry out similar work in England and Scotland. A detailed description of this vessel and her special equipment is given by Dr. Hjort, and the efficient and seamanlike way in which she must have been used could not have been better brought out than by the illustration showing the arrangement adopted for working two Petersen young-fish trawls and five tow-nets at the same time, and each at a different water-level. Equally striking are the successful results obtained by working a 50 -foot otter trawl at depths of from 400 to nearly 700 fathoms.

The section of the review dealing with hydrographical investigations, by Dr. B. Helland-Hansen, summarises the results which have been reached by a study of the salinities, temperatures, and currents of the Norwegian Sea. In the concluding paragraphs of the section attention is directed to a series of striking correlations between the hydrographical conditions prevailing in the Norwegian Sea and various climatic, fishery, and other phenomena, which appear to be affected by these conditions. Evidence is given for thinking that the amount of heat which the Gulf Stream conveys into the Norwegian Sea has a controlling influence on the winter climate of Scandinavia. From the amount of warmth in the water, recorded as early as the month of May, the author considers that it should be possible to tell whether the succeeding winter will be warmer or colder than usual. For the years 1902-6, in which the investigations took place, a low temperature in the Gulf Stream in the southern portion of the Nor-

1 "Review of Norwegian Fishery and Marine Investigations, 1900-8." Report on Norwegian Fishery and Marine Investigations, vol. ii., rgog,
N.o. r.

NO. 2096, VOL. 82] wegian Sea in May was followed by an early fishing for cod in Lofoten in the next winter, and vice versa. Other correlations of a similar character are also described.

In dealing with the plankton investigations, Dr. Damas gives an interesting account of his observations on the distribution of the medusa, Cyanea capillata, which is of considerable importance from its intimate association with the fry of the haddock, whiting, and cod. The fry of these fishes shelter themselves under the disc of the jelly-fishes, and are borne along with the latter in their passive wanderings. Shoals of these Cyanea have been traced from the shores of Jutland into the Skagerak, and thence along the coast of Norway to the north, carrying the young fish with them. Another medusa, Cyanea lamarcki, which has its home in the temperate Atlantic, occasionally reaches the west coast of Norway, accompanied by the fry of southern gadoid fishes, poor-cod, pout, and pollack.

But in addition to the more indirect, though not therefore less important or less fruitful, ways of approaching fishery problems, represented by the hydrographical and plankton investigations just mentioned, the Norwegians have devoted very considerable attention to the natural history of the fishes themselves. Dr. Damas writes on the distribution of the eggs and young stages of the gadoids, and gives also many results of the greatest significance concerning the age and growth of these fishes. By an examination of the scales it is now possible to determine with considerable certainty the age of each individual fish. Many catches of cod and haddock were examined in detail in this way, and the number of fish belonging to each year-group was ascertained. The important fact has been determined that fishes born in certain years largely preponderate in the catches, and the effect of these favourable breeding years can be traced in the catches year after year. Similar results have been obtained by Knut Dahl in the case of the herring. Thus in a sample of spring herring examined in the spring of 1907 the eightyear-old fish were in remarkable abundance. The same year-class, in the autumn of 1907 , was the most numerous of all the thirteen year-classes which composed the large herring of the coast of Helgeland. In the spring of 1908 several thousand spring herring were examined, and the nine-year-old fish were conspicuously abundant. In the autumn of 1908 , in a large sample of herring from Kristiansund, it was found that the $9 \frac{1}{2}$-year-old fish were more numerous than either the preceding or succeeding year-classes. In samples from the North Sea and Skagerak the data appear to indicate that here, also, the same yearclass predominated. It is clear that knowledge of this kind, if regularly and systematically collected, will enable estimates of the yield of the fisheries to be made some years before the fishing actually takes place, a result which cannot but be regarded as a triumph for the scientific method of approaching fishery problems.

Space has only allowed us to touch upon a few of the more striking features of this report. One would imagine that a perusal of it must convince the most sceptical of the value of the new knowledge which is now being rapidly made available as the result of the labours of the International Council for the Study of the Sea. Unfortunately, in this country the continuation of the work still, to some extent, hangs in the balance, but it is to be hoped that our Government, representing as it does by far the largest fishery interest of the countries bordering on the North Sea, will be induced to take a broad view of its responsibilities. 